\section{The clinician, the patient and the organisation: a crucial three sided relationship}

\section{Fiona Moss}

\section{Understanding and respecting the system of care essential for patient safety}

lne the UK about 5000 people die each year from hospital acquired infections. That equates to 65000 people since this journal was launched in 1992. This is an intolerable toll, which at least in part is linked to failure of healthcare professionals to clean their hands. Evidence that hand hygiene is effective in reducing infection is compelling and is available in the medical literature. ${ }^{1}$ So, why cannot hospitals institute and insist on the sorts of changes that make hand washing become part of actual practice?

Arguably, all improvements in clinical care require an organisational change. Failure to understand clinical practice in organisational terms can slow the introduction of new treatments as well as stall efforts to improve the quality and safety of care. For example, there was about a 10 year delay between publication of convincing research showing that thrombolysis, given appropriately, improves survival following a myocardial infarction and for this evidence based treatment to become part of routine practice. ${ }^{2}$ The knowledge of what worked was out there-but practice did not change. What was needed was a significant change in the organisation of emergency medical care. It seems that healthcare professionals and others are either unable to see the problems-and solutions-in organisational terms or, if they do, lack the skills to make the changes that will lead to improvement. And so, for years patients who suffered heart attacks were not offered life prolonging thrombolysis and today's patients continue to be exposed to unnecessary risk of contracting hospital acquired infections.

Other sectors, such as the airline and oil industries, have had considerable success in the pursuit of improved safety and better quality of service, and this experience may provide some lessons that can be transferred across to health care. However, unlike these other industries, many within health care, particularly clinicians, have an ambiguous relationship with their employing organisations-usually hospitals. I wager that all hospitals have a policy somewhere that states every one should clean their hands between seeing patients. Many healthcare workers do not do this simple thing: there is a chasm between organisational intention and the action of individuals. An organisational rule goes unheeded. People continue to die from hospital acquired infection. It is difficult to imagine people in the airline or oil industries not doing something that was so important for safety. But those organisations would surely have made the rule explicit; have provided training and made sure that the appropriate cleansing agent was always available in places where it was needed.

Descriptions of when things go horribly wrong usually include failures of the system of care, often with an element of care being given outside the usual process or system. Rarely are they stories of failure of intention to care for an individual. The story of Wayne Jowett, ${ }^{3}$ a 16 year old recovering from leukaemia who had forgotten to attend for consolidation chemotherapy illustrates this point. He arrived later than scheduled and, in order to help and to respond to his individual situation, the doctors who saw him (who were not his usual doctors and were not familiar with the organisational processes) arranged to administer his chemotherapy. A kind act but, in the end, one that led through a series of organisational errors to a clinical error and to Wayne's death. It is a story of the consequence of people who responded to an individual without understanding the dangers of working outside the system.

Learning to "buck" the system is a frequent early learning experience for many doctors. For example, hospitals in the UK do not allow pre-registration house officers (interns) either to prescribe or to administer cytotoxic chemotherapy. Although this "organisational rule" has been in force for several years, we sometimes find that it has been broken. This usually happens at night, when a nurse discovers that a patient has not been given chemotherapy; the person who should give it is no longer on duty and the "covering" doctor is called. Although this very inexperienced doctor and the nurse may both be aware that the doctor should not give the chemotherapy, neither perceives any real danger as the action needed is simply to attach an infusion bag to an already sited drip; both are concerned that the patient should get the treatment and so the treatment is given. An organisational rule is broken. Nothing happens, no one knows. A culture that ignores the system of delivery of care is enforced and the system becomes a little more dangerous.

Yet the literature on organisational improvement and customer focused service emphasises empowering individual workers to take responsibility and respond to the individual needs of their customers. So, how do you square this particular conflict? It must be by ensuring that empowerment also means training people to be able to do these tasks properly and understand the reasons for organisational rules and processes. Thus, nurses and pre-registration house officers don't assume that they are forbidden to give cytotoxic drugs because they are not capable but because they haven't been trained.

Healthcare professionals are trained very well to care for individuals but receive very little, if any, training in how to care for the system of healthcare delivery. Training about caring for and treating individuals is crucial. But it needs to be combined with learning about and respect for the system of care. Otherwise, focusing on individual needs and blind to the demands of the system of care, clinicians embark on actions that could jeopardise their patients' well being.

Clinical education needs to catch up with this changing world. Clinical autonomy, valued by clinicians, cannot be allowed to expose patients to risks that result from not respecting organisational guidelines. The education of clinicians needs to be extended to include an understanding of the impact of organisational behaviours on clinical care. Berwick et al ${ }^{4}$ suggested eight skills for quality improvement (see box) and, more recently, the US Accreditation Council for Graduate Medical Education has proposed a competency based model designed to encourage residents to learn about improvement principles. The six competencies are: patient care; medical knowledge; practice based learning and improvement; interpersonal and communication skills; professionalism and system based practice. ${ }^{5}$ 


\section{"New clinical skills" of quality management ${ }^{3}$}

- Ability to perceive and work in interdependencies

- Ability to work in teams

- Ability to understand work as a process

- Skills in collection, aggregation and analysis of outcome data

- Skills in "designing" health care practices

- Skills in collection, aggregation and analysis of data on process of work

- Skills in collaborative exchange with patients

- Skills in collaborative exchange with lay managers

Clinicians coming through such programmes should be better equipped to offer safer care in today's healthcare environment and, if hospitals provide the appropriate support and environment, will be able to put this training into practice. Most of those currently practising will not have had this training. These skills should be included within the revalidation and appraisal processes.

In the past, ignoring organisational rules and norms did not pose much danger to patients. As Cyril Chantler wrote: "Medicine used to be simple, ineffective and relatively safe; now it is complex, effective and potentially dangerous". ${ }^{\prime \prime}$ Hospitals as organisations need to work with clinicians to make sure that organisational guidelines are respected and adhered to. Insisting on hand hygiene would be a good start. To achieve this will require significant cultural change-and it demands clinical leadership and organisational commitment and support. But it might just be the break that is needed to encourage development of a culture in which organisational guidelines are observed. Hospitals, too, could take responsibility for ensuring that newly qualified doctors, who are very knowledgeable about drugs and therapeutics, learn how to prescribe safely-perhaps under the auspices of a "Director of Prescribing"7 It is never comfortable insisting that "rules" should be kept. Clinical practice is one area where they are not there to be broken.

This journal has reflected the development of quality and safety improvement for 13 years. Undoubtedly, much more is now known and understood about the extent of problems and some of the underlying causes. Important documents, including the two reports from the US Institute of Medicine, have influenced thinking and shaped the debate about the quality and safety of care worldwide. In the UK we have seen the implementation of clinical governance; the development of National Service Frameworks for a range of conditions and client groups; and the setting up of agencies such as the National Patient Safety Agency and the National Institute of Clinical Excellence. All this seems worlds away from the UK Medical Audit Programme, implemented in 1990 just before the launch of this journal, yet it is not clear just how much patients have benefited from all of this activity. Nevertheless, the increasing concern about the quality and safety of care and a developing research agenda ${ }^{8}$ should be grounds for cautious optimism.

The editorial team of QSHC is about to change. I hope that the new team will get the opportunity to report groundbreaking changes that show that knowledge about "what to do" has at last been translated into significant actions that truly make a difference for patients. In the meantime I thank the many authors, reviewers, and the editorial team who together enabled QSHC to reflect the burgeoning debate on quality and safety improvement over the past 13 years.

Qual Saf Health Care 2004;13:406-407. doi: $10.1136 /$ qshc. 2004.012872

Correspondence to: $\operatorname{Dr} F$ Moss, London Deanery, 20 Guilford Street, London WCIN 1DZ, UK; fmoss@londondeanery.ac.uk

\section{REFERENCES}

1 Stone SP, Teare L, Cookson BD. The evidence for hand-hygiene. Lancet 2001;357:479-80.

2 Antman EM, Lau J, Kupelnick B, et al. A comparison of results of meta-analyses of randomized control trials and recommendations of clinical experts. Treatments for myocardial infarction. JAMA 1992;268:240-8.

3 Toft B. External enquiry into the adverse incident that occurred at Queen's Medical Centre, Nottingham, 4th January 2001. London: Department of Health, 2001

4 Berwick D, Enthoven A, Bunker J. Quality management in the NHS: the doctor's role. BMJ 1992:304:304-8.

5 Leach DC. Changing education to improve patient care. Qual Health Care 2001; 10(Suppl II):ii54-8.

6 Chantler C. The role and education of doctors in the delivery of health care. Lancet 1999:353:1178-81.

7 Barber N, Rawlins M, Dean Franklin B. Reducing prescribing error; competence, control and culture. Qual Saf Health Care 2003;12(Suppl I):i29-32.

8 Thomson R, Carthey J. Research and development strategy, National Patient Safety Agency, 2004 (www.npsa.nhs.uk).
The best problem list for either country is probably the one in the landmark 2001 report "Crossing the Quality Chasm" issued by the Institute of Medicine (IOM), a branch of America's National Academies of Science. ${ }^{1}$ Summarizing decades of health services research and literally thousands of studies, the Chasm report recommended six "aims for improvement" as targets for the redesign of healthcare systems:

The task of building the best healthcare system in the world is well started in the UK

$\mathrm{P}$ ace your bets. Both the UK and the US are struggling to improve their troubled healthcare systems. Which is more likely to succeed? The two countries are strikingly similar in the problems they face, and equally dissimilar in their plans of action. I am a fan of both but, when bets are placed, my money will be on the UK.
- safety (reducing medical injuries to patients);

- effectiveness (increasing the reliability of evidence based care);

- patient centeredness (giving patients and carers far more voice, control, and competence in self-management); 
- timeliness (reducing waits and delays throughout the system);

- efficiency (reducing the total cost of care); and

- equity (closing racial and socioeconomic gaps in health status).

Rearranging the first letters, some organizations have taken to calling these the "S-T-E-E-E-P" goals.

Although the IOM's report addressed only American health care, its findings-and especially the six aims for improvement-pertain well to the UK and the NHS. The ongoing massive UK effort to improve the NHS-launched as the so-called "Modernisation Plan" in 1997-has involved massive new investments (raising the total UK expenditures on health care from its starting place of about $6.5 \%$ of the GDP closer to the EU average of about $8.5 \%$; compared with 15\% in the US!) and the creation of focused strategic plans-National Service Frameworks-that lay out dozens of new targets and approaches to care improvement for a variety of important clinical areas. The National Service Frameworks speak much the same language as the Chasm report, with a good deal more precision.

The profile of relative importance of the six aims differs somewhat between the two countries. Equity and excessive cost are far more urgent problems in the US, while timeliness ranks at the top of the NHS improvement agenda. Problems in safety, effectiveness, and patient centeredness plague us both. Overall, however, both nations can with confidence focus on the same "STEEEP" list of aims as a worthy agenda.

Why would I bet on success in the UK over the US? The biggest reason is simple: the UK has people in charge of its health care-people with the clear duty and much of the authority to take on the challenge of changing the system as a whole. The US does not. When it comes to health care as a nation, the US is leaderless. An immense resource for progress in improving the NHS - the key resource, in my view-has been the consistent focus of government, emanating from the Prime Minister personally, on raising the bar for NHS performance. The modernisation process sought to establish accountabilities, structures, resources, and schedules in the NHS that no one at all is in a position to establish in the pluralistic, chaotic, leaderless US healthcare system.

No one is thoroughly happy in the UK with the NHS modernisation program to date; it has stumbled occasionally, as any project of that level of ambition must. But no honest observer can fail to credit the process with immense productive change, headed for real measurable successes in a behemoth system that could easily seem unchangeable. Several objective evaluations - of which the most important is that sponsored by the Nuffield Trust in $2003^{2}$-find substantial gains underway in access, reliability, safety, and outcomes of NHS care. In the especially important arena of patient safety, the clear headed and courageous leadership of England's CMO, Sir Liam Donaldson, and the founding of the National Patient Safety Agency as a national resource, may soon catapult England into international prominence in systematically achieving new and unprecedented levels of patient safety.

"Three tough issues lie between the good successes that are almost in hand and the great ones that could be."

So, I will bet on the Brits. But I would offer even longer odds in their favor if a few large changes were made in the agenda for improvement of the NHS. Three tough issues lie between the good successes that are almost in hand and the great ones that could be.

\section{Unifying improvement work at the health economy level}

As an outsider, I would have thought that the globally funded, governmentally sponsored nature of the NHS would lead unerringly to sound development of community wide systems for the care of chronically ill people across the continuum of care. I would have thought that hospitals, community agencies, and primary care trustshaving, in effect, the same "owner" and "employer" (the public) and drawing on the same common pool of taxation-would work together seamlessly to assure flow, efficiency, integrated experiences, and common aims. But this is not the case. To my surprise, and to the UK's loss, hospitals and primary care trusts at the community level-the so-called "health economy" level-remain too often strangers, uncoordinated, mistrusting each other, convinced of conflicting aims, and thereby failing to achieve the needed flow and coordination of care for patients in desperate need of both. The NHS's long hospital lengths of stay and the feelings of disenfranchisement of chronically ill patients and carers, are only some of the symptoms of fragmentation.

The NHS will not achieve its full potential-the "STEEEP" goals will remain out of reach-unless and until the primary care trusts and hospitals at the community level are somehow brought more effectively into a common frame of planning, action, and patient care. Only a few local economies have shown success in this, due usually to nearly heroic leadership and hard work to maintain fragile coalitions. That plan is not robust enough for the nation as a whole. I do not necessarily recommend the rediscovery of the ancient "health authorities" as a vehicle, but some vehicle must be found to unify actions across the continua of care, or fragmentation will remain.

\section{Achieving authentic patient centeredness}

To a visiting American, consumerism and world class customer service seem a bit less developed in the UK than in the US. The same is true in health care. Viewed through American eyes, the modal British patient seems willingly more passive, and the modal British clinician habitually more controlling, than is probably best for either. The Chasm report uses the awkward term "patient centeredness" to denote the constellation of qualities of care that can give patients and carers power, knowledge, dignity, self-efficacy skills, respect for their diversity, and freedom of action. This is more than a political agenda (though it has political overtones); much sound clinical research shows that empowered, informed, activated patients tend to have much better outcomes and to use healthcare resources much more effectively than patients made helpless, silent, or passive by a system that takes too much control from them.

The NHS modernisation process still lacks a thorough commitment to patient centeredness of the type contemplated in the IOM vision. Perhaps the apparent British norms are just fine for Britain, and perhaps the pursuit of patient centeredness does not belong on the NHS agenda. But I doubt that. The next phase of development of a better NHS will go farther and faster, in my view, if stakeholders commit to a new level of control by patients and families of their own information and destinies in health care. It is important to know that British patients will not, in the first instance, demand that. They are trained too well. The question is not if they will ask, but rather if-once offered a new level of control and self-efficacy-they and the clinicians will come to appreciate the advantages of a new relationship that neither would have thought to request.

Linking the improvement of care to changes in professional education It is as important to build a future as it is to heal the present. In health care the "future" refers to our young 
professionals-doctors, nurses, therapists, and managers-who will inherit the NHS when we rest. From the viewpoint of improvement, and in pursuit of the "STEEEP" aims, our young professionals are emerging ill prepared to help. The education of health professionals generally lacks focus on the skills in systems thinking, statistical thinking, measurement, cooperation, group process, teamwork, and pragmatic "real time science," to name but a few disciplines that provide the foundation for effective citizenship in improvement. The result of missing this knowledge is a workforce that too often seems resistant to change and that lacks sufficient capacity to change the work it does.

So far, as I see it, the processes of change underway in the NHS lack effective connection to consonant changes in the education of young professionals. The omission is costly now, and will be more costly in the future as the workforce continues to be ill prepared to cope with-let alone to lead-a new, evidence based, reliable, patient centered, efficient, and safe system of care. That can easily change in the UK, but only with a totally new level of communication with and involvement of the agencies and leaders who are stewards of the educational systems - the Royal Colleges and others. Very promising changes are now underway in the relationships between the Royal College of Physicians and the leaders of the NHS, and these bode well for the future.

\section{CONCLUSION}

I do predict success for the UK in its efforts to build what can become the best healthcare system in the worldnothing less. The task is well started. These three adjustments-to organize care far better at the community level, to raise the bar on patient centeredness beyond what British patients may at first ask for, and to welcome and embed into the improvement process an agenda for change in the education of young professionals-will not be easy, but they are important enough to tackle hard and soon.

Qual Saf Health Care 2004; 13:407-409. doi: 10.1136/qshc.2004.012765

Correspondence to: D M Berwick, Institute for Healthcare Improvement, 375 Longwood Avenue, 4th Floor, Boston, MA 02215, USA: dberwick@ihi.org

\section{REFERENCES}

1 Institute of Medicine. Crossing the quality chasm: a new health system for the 21 st century. Washington, DC: National Academy Press, 2001.

2 Leatherman S, Sutherland K. The quest for quality in the NHS: a mid-term evaluation of the 10-year quality agenda. London: The Stationery Office, 2003.

\section{Challenges for an international guidelines collaboration}

\section{R Thomson}

\section{The Guidelines International Network is a welcome development for improving the quality of health care, but many challenges lie ahead}

$\mathrm{T}$ he emergence of evidence based guidelines may be one of the great successes of the evidence based medicine movement. We now have a mature process of development using literature review and appraisal, aligning strength of evidence and grading of recommendations. This has become an international movement and this global expansion is reflected in the development of the Guidelines International Network reported in this issue of QSHC. ${ }^{1}$

There have, indeed, been considerable successes, perhaps exemplified by the groundbreaking work of the National Institute of Clinical Excellence in the UK, building on earlier crafting of structured evidence based guidelines methods. ${ }^{2}{ }^{3}$ This industry was fashioned on the background of concerns about unexplained variations in practice and on the exponential growth of information with the problem for clinicians of remaining up to date with reading and assimilating the immense literature, let alone being able to appraise or assess it. ${ }^{4}$ Studies had shown that guidelines available were often widely variable in their content and in their likely impact upon quality of care if applied in practice. $^{56}$ Early guidelines development, based primarily on consensus methods, was found to be wanting and unlikely to produce valid guidelines. ${ }^{7}$

A poorly developed guideline could be as risky to the public health as a poorly developed drug, where there are extensive regulatory schemes for drug development and approval worldwide. Structured quality assured guideline development, perhaps led by national agencies, would solve these problems and be a more cost effective and safe way of providing valid guidance. More sophisticated and structured approaches have now taken precedence, although they are costly to undertake. Since its inception, NICE has produced over 40 evidence based guidelines. Other bodies have adopted or adapted this approach, both within and outside the UK. Similarly, there has been international development of an instrument to support guidelines appraisal (the AGREE instrument). ${ }^{8}$ On the back of this effective international collaboration has grown the latest development-the Guidelines International Networkwith the laudable objective "to protect the health of the general public by seeking to improve the quality of health care" $^{\prime \prime}{ }^{1}$

But all is not well with the movement. NICE has received criticism in the UK for its perceived failure to support effective dissemination of its guidance-a little unfair since it was not initially responsible for this. ${ }^{9}$ Nonetheless, it is now trying to address this key issue. Furthermore, the dissemination of full guidelines, formally targeted at users, may not be read by the clinicians at whom they are targeted-they may even prefer the patient summary versions. This is hardly surprising given the size of modern guidelines. A recent editorial in the $B M J$ graphs out the growth in size of hypertension guidelines as newer versions have been published in the UK and abroad. ${ }^{10}$ The second British Hypertension Society guidelines in 1993 were five pages long; the latest version in 2004 extends to 46 pages. There is therefore a problem for the dissemination and implementation of guidelines even if the development processes have been markedly improved.

Furthermore, evidence for the effectiveness of nationally developed guidelines is as yet incomplete, with some 
studies suggesting a significant impact and others suggesting little. ${ }^{11}{ }^{12}$ Evaluation of the impact of guidelines and guidelines programmes will be a significant issue. And, as the technology grows and is exported to more and more countries (including those with less well funded health systems), it is reasonable to ask whether there need be multiple national programmes or, at least, how such programmes might support one another.

The Guidelines International Network seeks to address these issues. The recognised importance of implementation is to be welcomed. The early conference and web developments look like a commendable start to this process. For example, the website contains much valuable material brought together in the same place for the first time and includes some topic areas such as a range of guidelines in a specific area such as asthma or ischaemic heart disease. However, it is unfortunate that the full searchable database of guidelines is available only to fee paying members. There is an undoubted need for a searchable site of quality assured guidelines; keeping that part of the site for members only may undermine the aims of the project. In addition, if the network is to achieve its aims, it will rapidly need to decide how it will assure the quality of the guidelines it decides to incorporate on its website. Those available in the topic based section range from fully developed evidence based guidelines using robust state of the art methods to others that have gone through a far less robust process. This not only leads to differences between the guidelines available on the site for the same clinical areas, but also risks repeating some of the problems that the movement was set up to address.

The widely accepted formal definition of guidelines as crafted by the Institute of Medicine--"systematically developed statements to assist practitioner and patient decisions about appropriate health care for specific clinical circumstances"13 - also throws up some challenges. The concentration to date has been on clinicians and, arguably, guidelines are rather paternalistic. This will be challenged by the increasing emphasis on patient choice and engagement in decision making. Indeed, there may be a significant tension between applying guidelines based on effectiveness and the drive to engage patients in shared decision making. How will guidelines work in this context?

When we look back in 50 years at this stage of the guidelines movement, the last decade will be seen as a pivotal point. Much progress has been achieved in stimulating high quality methods of appraisal and development and in finding ways of promoting guidelines in health systems. But many challenges remain. The Guidelines International Network has a big job ahead.

Qual Saf Health Care 2004; 13:409-410. doi: 10.1136/qshc.2004.012815

Correspondence to: Professor R Thomson, School of Population and Health Sciences Newcastle University Medical School, and Director of Epidemiology and Research, National Patient Safety Agency, London, UK; richard.thomson@newcastle.ac.uk

\section{REFERENCES}

1 Ollenschlager G, Marshall C, Qureshi S, et al. Improving the quality of health care: using international collaboration to inform guidelines programmes by founding the Guidelines International Network (G-I-N). Qual Saf Health Care 2004; 13:455-60.

2 Eccles M, Freemantle N, Mason J. North of England evidence based guidelines development project: methods of developing guidelines for efficient drug use in primary care. $B M$ 1998;316:1303-9.

3 Grimshaw J, Freemantle N, Wallace $S$, et al. Developing and implementing clinical practice guidelines. Qual Health Care 1995;4:55-63

4 Davidoff F, Haynes B, Sackett D, et al. Evidence based medicine: a new journal to help doctors identify the information they need. $B M J$ 1995;310:1085-6.

5 Thomson RG, McElroy H, Sudlow M. Guidelines on anticoagulant treatment in atrial fibrillation in Great Britain: variation in content and implications for treatment. BMJ 1998;316:509-13.

6 Unwin N, Thomson RG, O'Byrne AM, et al. Implications of applying widely accepted cholesterol screening and management guidelines to a British adult population: cross sectional study of cardiovascular disease and risk factors. BMJ 1998;317:1 125-30.

7 Grimshaw J, Russell I. Achieving health gain through clinical guidelines I: Developing scientifically valid guidelines. Qual Health Care 1993;2:243-8

8 Cluzeau FA, Littlejohns P, Grimshaw JM, et al Development and application of a generic methodology to assess the quality of clinical guidelines. Int J Qual Health Care 1999;1 1:21-8.

9 Secretary of State for Health. A first class service: quality in the NHS. London: Stationery Office, 1998.

10 Campbell NC, Murchie P. Treating hypertension with guidelines in general practice. BMJ 2004;329:523-4.

11 Ryan J, Piercy J, James P. Assessment of NICE guidance on two surgical procedures. Lancet 2004;363:1525-6.

12 Littlejohns P, Dillon A, Barnett D. Assessment of NICE guidance. Lancet 2004;364:135-6.

13 Institute of Medicine. Guidelines for clinical practice: from development to use. Washington: National Academic Press, 1992

\section{"Role driff" to unlicensed assistants: risks to quality and safety}

\section{H P McKenna}

\section{Health care assistants are increasingly filling the gaps in patient care}

$\mathrm{E}$ arlier this week I went to my local health centre for a routine blood test. I noticed that the uniformed woman approaching me with the needle drawn had the words "Health Care Assistant" on her badge. This is the first time I have had a sample of blood taken by a person who had no formally recognised training and whose role was unlicensed, unregulated and unsupervised. I proffered my arm-not without a little trepidation. The experience led me to wonder how many other health care assistants were practising in the health service, how many other invasive and non-invasive duties were they routinely undertaking, and how many members of the public were unaware that they were receiving care and treatment from such personnel. The answers to these questions raise further questions concerning quality and safety.

Modern health care is complex and hospitalised patients are often in the acute stage of their illness. Patient throughput has increased and new treatments and technologies have brought with them their own hazards. This is also true within the community where nurses are undertaking home based interventions which were recently only practised in the safety of a hi-tech clinical setting. From various countries there is evidence to indicate that better patient processes and outcomes can be achieved by having a high ratio of registered nurses in the clinical setting. ${ }^{12}$ More recently there have been reports that patient safety is positively 
linked to the presence of registered nurses. ${ }^{3}$ Contemporaneously, the literature is replete with percentage estimates of the amount of time nurses spend on low level basic tasks. It is believed that increasing the number of health care assistants would free nurses up to spend more time in direct patient care with the concomitant improvements in quality and safety. It is ironic therefore that, due to inducting, training and supervising the increasing number of health care assistants, the role that has been introduced to free up nursing time is actually consuming nursing time.

The junior doctors' hours initiative and the European Working Time Directive mean that nurses are being asked to take on roles that were once the remit of doctors. Wanless ${ }^{4}$ also recognised that workload might be shifted from doctors to nurses, and from nurses to health care assistants. This "role drift" is not new and not unique to nursing; allied health professionals, pharmacists and dentists are delegating what were previous core duties to assistants or technicians. Unfortunately "role drift" often occurs in an ad hoc fashion and may exceed its original scope.

Health care assistants undertake a number of duties previously carried out by nurses. A sample from a very long list includes catheter care, wound dressing, venepuncture, formulating patient care plans, setting up and monitoring diagnostic machines, setting up infusion feeds, giving injections, taking charge of shifts, monitoring use of cardiotocograph machines, providing advice on parenting skills and breast feeding. According to the literature, much of this work is unsupervised. Because of their increasing numbers (estimated to be over half a million in the UK), and hence visibility in the clinical setting, health care assistants are also involved more in student learning.
Despite the fact that they are at the front line in providing care, there is no statutory duty for health care assistants to have any training. Invariably, such training is considered to be the responsibility of their employing organisation and this has led to informal and nonstandardised training programmes. While national vocational qualifications (NVQs) were introduced in the UK in an attempt to standardise the training of health care assistants, their introduction has not been widespread. This means that their role often varies depending upon the country and the clinical area in which the person is employed. This lack of standardisation of their role is a potential threat to safety and quality.

Attempts have been made to develop skills, experience, and career ladders for health care assistants. While such recognition is laudable, it is still the case that many remain unlicensed and unregulated. There is no system in place whereby a health care assistant's criminal record or level of competence can be checked. There have been some well publicised cases where patients have been subjected to abuse at the hands of health care assistants who were dismissed from their work and started employment in another setting shortly afterwards. Unlike most health professionals, there are no mechanisms in place to alert the new employer to past offences. There have also been reports that some nurses were removed from the nursing register and began working as health care assistants, particularly in the nursing home sector.

There are proposals for extending regulation to those staff who have a direct impact on patients. Meanwhile, within this climate of regulation uncertainty, many nurses depend vicariously on health care assistants to deliver unsupervised direct patient care without being certain of the safety or quality of such care. According to their Code of
Professional Conduct, nurses should not delegate duties to health care assistants if they are concerned that the care undertaken will not be up to the standard expected by a nurse who would normally undertake the task. However, it is impossible to ensure delegation is appropriate if roles are not clearly defined and training is ad hoc. If nurses are under pressure, they may allow health care assistants to carry out unsupervised tasks they would not otherwise consider, which could result in patients being put at risk.

In a climate of a global shortage of registered nurses and demands for them to embrace a "role drift" to medical duties, there is an increasing reliance on health care assistants to fill the gaps in care. The majority of health care assistants are caring and conscientious individuals who are often pressurised to go beyond their level of competence to perform duties for which they are not qualified-potentially endangering patients. The health care assistants themselves are powerless, waiting on policymakers to sort out the mess while they do their best in an unenviable situation.

Qual Saf Health Care 2004;13:410-411. doi: 10.1136/qshc.2004.012757

Correspondence to: Professor H P McKenna, Faculty of Life and Health Sciences, School of Health Sciences Nursing, School of Health Sciences, University of Úlster, Jordanstown BT37 0QB, UK; hp.mckenna@ulst.ac.uk

\section{REFERENCES}

1 McKenna H. Nursing skill mix substitutions and quality of care: an exploration of assumptions from the research literature. J Advan Nurs 1995;21:452-9.

2 Zimmermann P. The use of unlicensed assistive personnel: an update and sceptical look at a role that may present more problems than solutions. $J$ Emerg Nurs 2000;26:312-7.

3 Institute of Medicine. Keeping patients safe: transforming the work environment of nurses. Washington, DC: Institute of Medicine, 2003.

4 Wanless D. Securing our future health: taking a longterm view. London: The Public Enquiry Unit, 2002. make a significant difference, and in the right direction?

\section{Researching doctors' decisions}

\section{J Dowie}

\section{Description without prescription is like diagnosis without treatment}

W

hy bother trying to discover how clinicians make decisions? Would it really make any difference to the quality of care if we knew more about their decision making processes? Is there any basis for the
Probably not. During the three decades since the pioneering work of Elstein et al, ${ }^{1}$ numerous studies of the decision making behaviour of clinicians-and, indeed, professionals in many fields-have yielded only one relevant finding. Insofar as we can make inferences about how they decide what to do by observing their behaviour or interrogating them, their decisions and decision processes vary enormously. Even when researchers are able to come 
up with generalisations about the diagnostic or therapeutic processes of practitioners, these are often weakly supported and/or highly restricted in their coverage. Above all, they are analytically vague. This is not surprising because, even though some explicitly analytical reasoning is usually reported by practitioners, the expertise applied in professional decision making appears to be substantially intuitive, involving significant amounts of either intuitive pattern recognition or intuitive regression across "multiple fallible indicators". ${ }^{2}$ The disappointing results from the vast amounts of money and effort put into developing "expert systems" of the production rule ("if-then") sort have merely confirmed that much of the time experts literally do not know what they are doing. This does not, of course, imply that what they are doing is not appropriate and may indeed be optimal. What it does mean is that even skilled "knowledge engineers" cannot extract the inaccessible elements of expertise for use in either practice guidelines or professional training.

Given the undoubted existence and significance of intuitive expertise, what is the point of attempting to describe the decisional behaviour of doctors? Setting aside the aim of acquiring knowledge for its own sake, which justifies the interest of the academic psychologist, does descriptive theorising and empirical research without an explicit prescriptive standard have any practical use for either practitioner decision making or professional education? Why spend any time on descriptive theorising unless one knows what is the best decision or best decision process, or both? Without a prescriptive basis, the use of descriptive results in improving the quality of care is zero and this is true whether the adopted prescriptive basis is decision analysis, the practice of some person or some group defined as best decision practice, or any other criterion.

It is, of course, methodologically imperative that the prescriptive basis be defined before any research study. Otherwise one will simply be defining the prescriptive as what happens: this is the way doctors do make decisions, therefore this is the way they should make decisions. Alternatively, one will end up simply pointing out the existence of variation, in itself of no practical use except insofar as it acts as a stimulus to identifying the necessary prescriptive basis. ${ }^{3}$

If one does have an accepted prescriptive basis for quality care, why not just apply it and teach it to the extent either is possible? Forget the descriptive challenge except as an aid in determining the most effective way to identify the obstacles to implementing the prescriptive.

But there is a major difficulty lurking here-one that only an explicitly analytical prescriptive standard, such as that offered by decision analysis, satisfactorily exposes. Many studies of practitioner decision making which seek to evaluate the quality of decisions (either explicitly or implicitly) fail to recognise, or sufficiently emphasise, two things. Firstly, that there can be no such things as a gold standard verdict on management decisions of the sort that is possible on diagnostic judgements. Decisions involve value judgements as well as probability judgements and the prescriptive bases of the two types are very different, if indeed one exists for value judgements. Secondly, that any evaluation of a decision by a prescriptive standard must logically be on an ex ante basis. One cannot sensibly evaluate a decision by its ex post outcome, as is often suggested.

One can certainly set up a prescriptive standard against which to evaluate an ex ante probability judgement offered as to whether this patient has appendicitis or this child has been abused. But unless one can also set up a gold standard on the value side of the decision, which will involve establishing the relative value/disutility to be assigned (ex ante) to the false positive and false negative errors always possible under irreducible uncertainty, one cannot evaluate the decision. In order to evaluate the decision one must be able to identify what the best one was in this particular case, and this necessitates identifying the best available probabilities and most appropriate value judgements - in both cases at the moment of decision. Evaluation of decisions is therefore contingent on agreement on the values and preferences regarded as the appropriate ones at that moment, Ethically, these should be those of the owner(s) of the decision-the patient in the private clinical situation or several constituencies in the public health and health services. If there is insufficient agreement on these-and some variation in values may be consistent with the same choice of action-no agreed evaluation of the quality of a decision will be possible.

Why the ex ante basis? Under uncertainty it is possible that the best decision will produce the worst outcome and vice versa. One can obviously establish, by an ex post gold standard procedure, whether this patient actually had appendicitis or whether this child had actually been abused. (The latter example illustrates the difficulty of establishing 24 carat gold standard verdicts or, in many cases, ones of very few carats.) But while the judgement/ex post outcome observation in this case can be added to the database for future decisions-improving the assessments of the sensitivity and specificity of the professional concerned-it cannot, by definition, change the evidence that was available at the time the original decision was made. It is therefore irrelevant to the evaluation of that decision. (The existence of a treatment effect, as in the ventilation case investigated by Kostopoulou and Wildman, ${ }^{3}$ is a serious problem for the development of the evidential database.) Equally irrelevant is the experienced utility or disutility of the actual outcome, as opposed to the anticipated utility or disutility of the possible outcomes at the moment of the decision.

Description without prescription is as useful as diagnosis without treatment.

Qual Saf Health Care 2004;13:411-412. doi: 10.1136/qshc.2004.010967

Correspondence to: Professor J Dowie, Public Health and Policy Department, London School of Hygiene and Tropical Medicine, London WCIE 7HT, UK; jack.dowie@|shtm.ac.uk

\section{REFERENCES}

1 Elstein AS, Shulman LS, Sprafka SA. Medical problem solving. Cambridge MA: Harvard University Press, 1978.

2 Hammond KR. Human, judgment and social policy:irreducible uncertainty, inevitable error unavoidable injustice. New York: Oxford University Press, 1996.

3 Kostopoulou O, Wildman M. Sources of variability in uncertain medical decisions in the ICU: a process tracing study. Qual Saf Health Care 2004; 13:272-80. 